\title{
Current Health Care Condition in Yemen (Aden)
}

\author{
Anes Salah Mohammed Hasan ${ }^{1, *}$, Mehmood Gulab Sayyad ${ }^{2}$ \\ ${ }^{1}$ Department of Health and Biomedical Sciences, Symbiosis International University, Pune, India \\ ${ }^{2}$ Department of Statistics, Abeda Inamdar Senior College, Azam Campus, Pune, India \\ Email address: \\ anisyem999@gmail.com (A. S. M. Hasan),mgsayyad@gmail.com (M. G. Sayyad) \\ *Corresponding author
}

\section{To cite this article:}

Anes Salah Mohammed Hasan, Mehmood Gulab Sayyad. Current Health Care Condition in Yemen (Aden). American Journal of Clinical and Experimental Medicine. Vol. 6, No. 1, 2018, pp. 18-21. doi: 10.11648/j.ajcem.20180601.13

Received: November 25, 2017; Accepted: December 12, 2017; Published: January 25, 2018

\begin{abstract}
Patient safety is a serious global public health issue. In recent years the importance of improving patient safety has been a major concern all over the world. The government of Yemen, like governments of other developing countries has been providing a wide range of free healthcare services to its people over a long period of time. The increase in health related problems in Yemen is due to lifestyle changes and lack of adequate care by the hospitals. Accordingly, the Ministry of Public Health and Population (MoPHP) in Yemen realized that the public sector alone is no longer capable of providing necessary health care for the people of Yemen and therefore privatized the sector to a large extent. This paper is aimed at focusing on the current health care situations available in Yemen. The secondary data of the health care related aspects are presented and discussed retrospectively. We present a review of current health care status in Yemen through a retrospective data with reference to Aden city and also discuss the possible measures need to be implemented in order to improve the situation. The paper discusses the evaluation of the health care standards in Yemen and also explores the reasons for medical tourism of Yemeni nationals to other countries like India.
\end{abstract}

Keywords: Health Care Situation, Medical Tourism, Aden, Yemen

\section{Introduction}

Patient safety has been a serious global public health issue. Estimates show that in developed countries as many as one in 10 patients is harmed while receiving hospital care. Of every hundred 100 hospitalized patients at any given time, 7 in developed and 10 in developing countries will potentially acquire health care-associated infections. Hundreds of millions of patients are affected due to this worldwide each year. In recent years, countries have increasingly recognized the importance of improving patient safety. In 2002, WHO Member States agreed on a World Health Assembly resolution on patient safety. There are an estimated 1.5 million different medical devices and over 10000 types of devices available worldwide. [1] The majority of the world's population is denied adequate access to safe and appropriate medical devices within their health systems. More than half of low-and lower-middle income countries do not have a national health technology policy which could ensure the effective use of resources through proper planning, assessment, acquisition and management of medical devices.

The government of Yemen, like governments of other developing countries has been providing a wide range of free healthcare services to its people over a long period of time. However, despite the significant progress Yemen has made to expand and improve its health care system over the past decade, the system remains severely underdeveloped. Total expenditures on health care in 2002 constituted 3.7 percent of gross domestic product. In that same year, the per capita expenditure for health care was very low, as compared with other Middle Eastern countries-US\$58 according to United Nations statistics and US\$23 according to the World Health Organization. According to the World Bank, the number of doctors in Yemen rose by an average of more than 7 percent between 1995 and 2000, but as of 2004 there were still only three doctors per 10,000 persons. In 2003 Yemen had only 0.6 hospital beds available per 1,000 persons [1-2]. Health care services are particularly scarce in rural areas; only 25 percent of rural areas are covered by health services, as compared with 80 percent of urban areas. Emergency 
services, such as ambulance service and blood banks, are non-existent. Most childhood deaths are caused by illnesses for which vaccines exist or that are otherwise preventable. According to the Joint United Nations Programme on HIV/AIDS, in 2003 an estimated 12,000 people in Yemen were living with human immunodeficiency virus/acquired immune deficiency syndrome (HIV/AIDS) [2].

The increase in health related problems in Yemen is due to lifestyle changes and lack of adequate care by the hospitals and elderly are indeed more likely than younger groups to suffer from chronic diseases such as diabetes, heart disease etc. Also, the prevalence of substance abuse mainly in the form of tobacco use has been very common among the Yemeni population. According to a study by C. Scheifele et al, a remarkably high prevalence of oral pre-cancerous lesions, such as oral lesions with $27 \%$, and oral squamous cell carcinoma $(1 \%)$ in Yemeni shammah users has been reported [3]. Shammah is a complex smokeless tobacco mixture consisting of powdered tobacco leaf, slaked lime (calcium carbonate), ash, oil and other substances, e.g. black pepper, mint, and flavours.

In view of increasing burden of health care related services, the Ministry of Public Health and Population (MoPHP) in Yemen realized that the public sector alone is no longer capable of providing necessary health care for the people of Yemen and therefore privatized the sector to a large extent [4].

Patient safety is an important component of health care quality. It includes the measurement of patient safety aspects which is a top priority in developed countries today, however the patient safety aspects are not well appreciated in the developing countries such as Yemen. As a result recently there has been a massive travel by Yemeni nationals in the form of medical tourism in other developing countries like India.

This paper discusses the current health care facilities and their quality aspects available in Yemen with special reference to Aden. The secondary data of the health care related aspects is presented and discussed retrospectively.

\section{Materials and Methods}

The retrospective secondary data of health care related aspects in Yemen with special reference to Aden is presented mainly in three sections viz. 1) current heath indicators 2) availability of health care facilities and 3) patient care quality aspects.

\section{Results}

Yemen remains in the early stages of the epidemiological transition, with morbidity and mortality from communicable diseases still predominating over non-communicable diseases, and with high levels of malnutrition prevailing. The most common and serious health conditions Yemen faces are diarrhea, malnutrition, complications of pregnancy, acute respiratory infections, and malaria. AIDS is becoming increasingly prevalent, and non-communicable conditions such as cancer, heart disease and trauma are also on the rise (third five year plan MOPH\&P 2005) [5].

\subsection{Current Health Indicators}

The challenge of improving the quality of life in Yemen can be understood by reference to basic indicators. Basic health indicators are shown in table 1 and it is clear that the infant mortality rate 74 per 1,000 , the under-five mortality rate of 102 per 1,000, and average life expectancy of 63 years-are much improved in the year 2004 since 1990. Malnutrition affects almost half of children under five. About one quarter of newborns is of low birth weight raising their chance for catching diseases. Maternal mortality rate still one of the highest in the world and this reflecting the low quantity and quality of maternal services. The recent data on causes of mortality and the morbidity is not available precisely across the country. Table 2 shows the distribution of top six causes of mortality and morbidity according to retrospective information collected during third five year plan (2005) [6]. The leading causes of mortality were the infectious diseases such as diarrhoea, diseases of respiratory system, the diseases of digestive system, complications during pregnancy, injuries ad poisoning, and the diseases of circulatory system. While most of the leading causes of morbidity still remain nearly the same, the percentages may vary but incidence of diarrheal disease, malnutrition, complications of pregnancy, acute respiratory disease, malaria and Schistosomiasis or Bilhasiasisstill outnumber the other causes of morbidities [6]. During the last 10 years the prevalence of chronic and cardio-vascular diseases has mainly increased due to changes in the lifestyle of the local population.

Table 1. Basic health indicators in Yemen.

\begin{tabular}{lllll}
\hline Indicator & $\mathbf{1 9 9 0}$ & $\mathbf{1 9 9 5}$ & $\mathbf{2 0 0 0}$ & $\mathbf{2 0 0 4}$ \\
\hline Life expectancy at birth & 46 & 57 & 59 & 63 \\
Infant mortally rate & 130 & 81 & 75 & 74 \\
Probability of dying before $5^{\text {th }}$ birthday $/ 1000$ & 123 & 121 & 105 & 102 \\
Maternal mortality rate & -- & -- & $351^{*}$ & 365 \\
\% normal birthweight babies & 70 & 74 & 91 & 78 \\
Prevalence of malnutrition & 56 & -- & 42 & $53-12$ \\
\hline
\end{tabular}

Source: Civil Society (CSo) 1995-2000-2003, Poverty reduction strategy papers (PRSP)*. 
Table 2. Top 6 causes of mortality / morbidity in Yemen.

\begin{tabular}{lll}
\hline Rank & Mortality & Morbidity \\
\hline 1 & Infectious and Parasitic diseases including diarrhoea & Diarrheal diseases \\
2 & Diseases of the Respiratory System & Malnutrition \\
3 & Other Diseases of the Digestive System & Complication of pregnancy and delivery \\
4 & Complications of Pregnancy, child birth and puerperium & Acute respiratory disease. \\
5 & Injuries and poisoning & Malaria \\
6 & Diseases of the circulatory system & Schistosomiasis or Bilhasiasis \\
\hline
\end{tabular}

Source: Third Five-Year Plan (YP) 2005 Note: there is no separation between mortality and morbidity causes in the third 5YP. So the mortality causes were taken from the Second $5 \mathrm{YP}$.

\subsection{Availability of Health Care Facility}

\subsubsection{Situation in Overall Yemen}

Table 3 shows the distribution of health care human resource availability in Yemen per 100,000 population. It is important to note that the number of human resources such as nurses, medical assistants, midwives and other laboratory technicians have shown considerable rise since 1990, however the number of human resources such as physicians, dentists and pharmacist did not show any significant increase since 1990 [6].

\subsubsection{Situation in Aden, Yemen}

Table 4 presents the information related to the overall health care facility available in Aden as on January 2017 as per a pilot survey conducted in order to plan a comparative study between India and Yemen. According to this survey, there are a total of 13 hospitals available in Aden, of which 4 are private and 9 are private. Private hospitals cater the services to $61.5 \%$ of the total hospital beds available in the city. Of 9 private hospitals, $77.7 \%$ and of 4 hospitals $50 \%$ hospitals have the facility of ICU / NICU. Of the total staff working in the hospitals, majority were working in private hospitals $(72.3 \%)$. Of the total 30542 patients that visited various hospitals in Aden city during the previous month (December 2016), 76.3\% preferred private hospital and remaining visited the public hospitals. Patient to doctor ratio is also a major concern in the public as well as private hospitals. In the previous month, on an average 3 doctors in public and 5 doctors in private hospitals were available per 1000 patients.

Table 3. Human resource availability for health care in Yemen.

\begin{tabular}{lllll}
\hline Personnel per 100, 000 population & $\mathbf{1 9 9 0}$ & $\mathbf{1 9 9 5}$ & $\mathbf{2 0 0 0}$ & $\mathbf{2 0 0 4}$ \\
\hline Physicians & 23.3 & 22.0 & 19.1 & 22.8 \\
Dentists & 1.2 & 1.4 & 1.3 & 1.3 \\
Pharmacists & 4.4 & 6.4 & 7.0 & 8.0 \\
Nurses & 29.8 & 39.6 & 29.7 & 51.1 \\
Medical assistant & 5.1 & 7.0 & 5.2 & 7.4 \\
Midwives & 1.7 & 2.6 & 7.1 & 13.6 \\
Laboratory technicians & 4.4 & 3.9 & 5.2 & 9.9 \\
Others & 23.9 & 8.8 & 22.0 & 78.0 \\
\hline
\end{tabular}

Table 4. Distribution of health care facilities available in Aden as on January 2017.

\begin{tabular}{|c|c|c|c|c|c|c|}
\hline Hospital & $\begin{array}{l}\text { No. of } \\
\text { hospital }\end{array}$ & No. of beds & $\begin{array}{l}\text { No. of Hospitals with } \\
\text { ICU/PICU/NICU availability }\end{array}$ & No. of staff & $\begin{array}{l}\text { No. of patients per } \\
\text { month }\end{array}$ & $\begin{array}{l}\text { Patients to Doctor } \\
\text { Ratio }\end{array}$ \\
\hline Public & 04 & 1408 & 02 & 1032 & 7232 & 3 per thousand \\
\hline Private & 09 & 2250 & 07 & 2700 & 23310 & 5 per thousand \\
\hline Total & 13 & 3658 & 09 & 3732 & 30542 & -- \\
\hline
\end{tabular}

\subsection{Patient Care Quality Aspects}

Patient safety is considered to be the major foundation for high-quality health care services. Due to the increased burden of health care services and the poor patient to doctor ratios, the quality health care services are not well appreciated in Yemen. As a result majority of the Yemeni nationals travel abroad and spend huge amount for getting quality health care services [7-8]. Table 5 shows the distribution of Yemeni nationals who had travelled to India during previous one year (2013-14) for seeking the variety of health care treatments as per the information obtained through Embassy of Republic of Yemen regarding medical tourism. It is clear from the table that, of the 25,000 people who visited the foreign countries, 18,000 have landed in India and the remaining went in other countries such as Saudi Arabia, Sri Lanka etc. It is important to note that of 18,000 patients who travelled to India, over $60.0 \%$ have landed in Pune (Maharashtra) for the specialised treatments. However the details on exact illness and reason could not be traced through the records of Government of Yemen. Nonetheless, through a pilot survey as mentioned in the above section, we tried to explore the reasons for the travel from some of the patients who were admitted in a few hospitals in and around Pune. The major reasons include the lack of health care quality service, lack of availability of super-speciality and relatively higher cost of treatment etc.

Table 5. Distribution of Yemeni nationals who visited other countries for the health care services (medical tourism data).

\begin{tabular}{ll}
\hline Country visited & No. of cases (2013-14) \\
\hline India & 18,000 \\
Other countries & 7,000 \\
Total & 25,000 \\
\hline
\end{tabular}

\section{Discussion}

In this paper we present the health care information of Yemen mainly in three sections viz. 1) current heath indicators 2) availability of health care facilities and 3) 
patient care quality aspects. Based on the retrospective data the basic health care indicators such as average life expectancy, infant mortality rate, maternal mortality rate etc have improved considerably but are still not satisfactory when compared it with the other developing countries such as India and China [9-12] Though recently the health care facilities have been improved compared what they were in the late $90 \mathrm{~s}$, still the improvement does not seems to be satisfactory when compared to the other developing countries [9-12]. Relatively higher number of Yemeni medical tourists visiting the other countries seeking the better treatment should be a major cause of concern in front of the Yemeni Government. In this paper we present the retrospective information related to health care standards and services available in Yemen, further studies are required to perform the precise comparisons with the other developing countries such as India and China by means of structured and validated questionnaires. It is also important to study the perspective of health care workers involved regarding the problems faced by them in providing the health care services across Yemen.

\section{Conclusions}

The healthcare standards in Yemen though improving but are not well appreciated in comparison with the other developing countries. It is essential for the Policy makers of Yemen to strengthen the heath care standards considerably by adopting the Western model. The political instability, economical and International crisis have further worsened the scope of development in the country. It is important for the Government to concentrate on capitalizing the resources available across the country by strengthening the development of advanced infrastructure and educational systems with a major focus on improving the overall health care quality standards.

\section{Acknowledgements}

The help by the employees of embassy of Republic of Yemen, New Delhi for providing the medical tourism data is highly appreciated.

\section{References}

[1] Internet Reference:

"http://www.who.int/features/factfiles/patient_safety/en/".

[2] Country Co-operation Strategy for WHO and the Republic of Yemen (2008-2013). [Homepage on the Internet-cited 2015 Oct 20].

[3] Scheifele C et al. (2006). Prevalence of Oral Cancer and Potentially Malignant Lesions among Shammah Users in Yemen. Yemeni Health \& Medical Research Journal 3 (11).

[4] Abbes A (2000). Revision of Existing Laws in the Private Health Care Sector. Consultancy report. Sana'a: MoPHP.

[5] MoPHP (2005). Annual Health Statistical Report for 2002, 2003. Sana'a: General Directorate for Health Statistics and Informatics.

[6] Health system profile-Yemen (2006). Regional health systems observatory-EMRO. WHO.

[7] Anbori et al. (2010). Patient satisfaction and loyalty to the private hospitals in Sana'a, Yemen. International Journal for Quality in Health Care. 22 (4): 310-5.

[8] WB HDS (1998). The Yemeni Health care Consumer: Out of Pocket Costs and Health care Utilization.

[9] Ministry of Health and Family Welfare (2015). "Draft National Health Policy 2015".

[10] Yemen country profile. Library of Congress Federal Research Division (2006). This article incorporates text from this source, which is in the public domain.

[11] Sai Ma et al. (2008). A comparison of the health systems in China and India. RAND-centre for Asia pacific policy.

[12] United States Department of State, "Cape Verde: Country Specific Information" http://travel.state.gov/travel/cis_pa_tw/cis/cis_1083.html. 